\title{
Surgical Excision of Fibroma Followed by Elbow Fold Flap in a Non-descriptive Dog
}

\author{
M. Gokulakrishnan ${ }^{*}$, L. Nagarajan ${ }^{2}$, Denise A. Almeida ${ }^{3}$ and S. Gowsalya ${ }^{3}$ \\ ${ }^{1}$ Department of Clinics, Madras Veterinary College, TANUVAS, Chennai, India \\ ${ }^{2}$ Department of Veterinary Surgery and Radiology, Madras Veterinary College, TANUVAS, \\ Chennai, India \\ ${ }^{3}$ Madras Veterinary College, TANUVAS, Chennai, India \\ *Corresponding author
}

\section{A B S T R A C T}

\section{Keywords}

Fibroma, Surgical excision, Wide defect, Elbow fold flap, Dog

Article Info

Accepted:

15 February 2020 Available Online: 10 March 2020
A 13 year old, male, intact, non-descriptive dog weighing $23 \mathrm{~kg}$ was brought to Madras Veterinary College Teaching Hospital at small animal out patient surgery unit, with a history of progressive painful swelling at the left elbow joint. On clinical examination the mass was hard, irregularly contoured and the pet evinced mild pain on palpation. Fine needle aspiration cytology was performed to identify the nature of cells and to confirm the diagnosis which revealed Fibroma. Survey Radiograph of the left elbow region and the thorax were taken to rule out any bony involvement and metastasis if any. Since the results revealed absence of metastasis and bony involvement, surgical excision was planned. Routine heamato-biochemical profiles were performed to rule out organ health, which revealed animal had neutrophilia, increased ALP and altered $\mathrm{Ca}: \mathrm{P}$ ratio. All other parameters were within the normal range. Surgical excision of the fibroma resulted in a wider defect which was non apposable through standard suturing procedures. Hence, an elbow fold flap was performed. Appropriate antibiotics and analgesics were prescribed and dressings were done on alternate days until would healing was noticed. Animal recovered uneventfully.

\section{Introduction}

A 13-year-old, male, intact, non descriptive dog, weighing $23 \mathrm{~kg}$ was brought to Madras Veterinary College Teaching Hospital at
Small Animal Out Patient Surgery Unit with a history of progressive painful swelling at the left elbow joint. The owner reported that the pet had difficulty in locomotion and evinced discomfort during rest. On clinical 
examination, the mass was approximately 5.2 $\mathrm{cm} \times 4.3 \mathrm{~cm}$ in dimensions, was hard and irregularly contoured. The pet evinced mild pain on palpation. The mass extended from medial to latero-cranial aspect of the elbow joint. Aspiration of the mass revealed absence of transudates, which was not indicative of elbow hygroma. Fine needle aspiration cytology was performed to identify the nature of cells and to confirm the diagnosis which revealed Fibroma at the elbow region. The FNAC findings revealed presence of spindle cells with oval and elongated nuclei along with indistinct nucleus. In addition, tapering cytoplasm were also observed. A dorsopalmar and lateral survey radiograph of the left elbow region was taken to rule out any bony involvement, in addition, a lateral thorax Radiograph was taken to rule out any metastasis, if any. Since the results revealed absence of metastasis and bony involvement, surgical excision was planned. Routine heamato biochemical profiles were performed to rule out organ health, which revealed neutrophilia, increased ALP and altered Ca:P ratio. All other parameters were within the normal range. The dog was fasted 12 hours prior to surgery. The pet was pre-medicated with diazepam and butorphanol at the dose rate of $0.5 \mathrm{mg} / \mathrm{kg} \mathrm{BW}$ and $0.1 \mathrm{mg} / \mathrm{kg} \mathrm{BW}$ intravenous respectively. Anesthesia was induced with propofol @ $4 \mathrm{mg} / \mathrm{kg}$ BW intravenous, following which intubation was performed using 6.0 I.D. cuffed endotracheal tube. Anesthesia was maintained with Isoflurane $1.5 \%$ MAC with oxygen as a carrier gas using a closed breathing circuit. The animal was placed in right lateral recumbency with the left forelimb secured at an elevated position. The surgical site was aseptically prepared, the donor site was tentatively dimensioned. Surgical excision of the fibroma was performed using thermocautery in order to arrest hemorrhage and to minimize blood loss. Surgical excision of the Fibroma resulted in a wider defect which was non apposable through standard suturing procedures. Hence, an elbow fold flap was planned. A felt pen marker was used to delineate the margins of the flap prior to incision. B.P No. 11. blade was used to incise the margins of the flap following which the flap was undermined without damaging the sub-dermal plexus and was elevated under illumination. The flap was later oriented towards the post excisional defect and stay sutures were applied accordingly. The leg was maneuvered to assure that sufficient skin was available to withhold the tension and provided appropriate apposition. Intradermal sutures were done using PGA 2-0 round bodied suture material following which skin was sutured with 2-0 Polyamide in a criss cross pattern. Soft cotton bandaging was done. Appropriate antibiotics and analgesics were prescribed and dressings were done on alternate days until would healing was noticed. Subjective evaluation of the flap was performed to evaluate flap uptake which revealed complete growth of hair, apprehensive vascularity and complete flap uptake, therefore. Animal recovered uneventfully. Collagen-rich non-neoplastic and neoplastic lesions are reported in the canine skin. They include fibromas, nodular dermatofibrosis, collagenous hamartomas, fibroadnexalhaematoma, dermatofibromas and fibrosarcomas (Ashraf et al., 2016). Cutaneous fibroma was rarely diagnosed in dogs. It comprised $2.8 \%$ of the total diagnosed canine skin neoplasms (Anderson et al., 2004). The skin is the most common site of occurrence of canine neoplasms. The presence of many ulcerative wounds in the neoplasm could be attributed to self licking and biting of the neoplasm as observed in the present case. Closing skin wounds overlying the olecranon can be difficult in dogs because of the lack of excess skin, susceptibility to repeated impact, compression, and tissue tension (Bowler et al., 2001). In debilitated dogs that sleep on their sides, wounds are 
more prone to bacterial infection and abscessation, dehiscence, and incomplete wound healing. (Aperand Smeak, 2003). Closure techniques for wounds over the elbow area include healing by second intention, simple appositional wound closure, local skin flaps, axial pattern flaps,

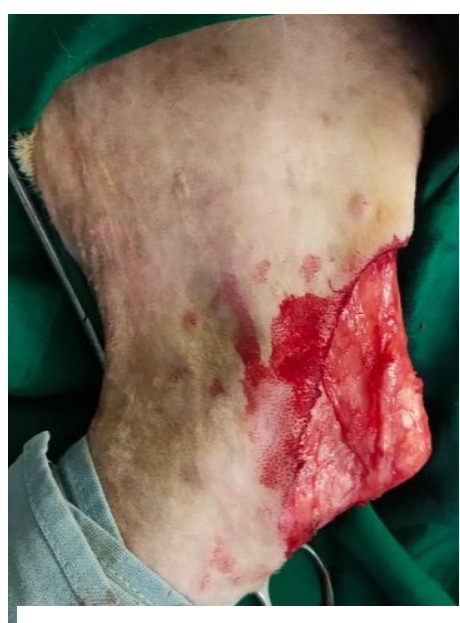

Post Excision Defect

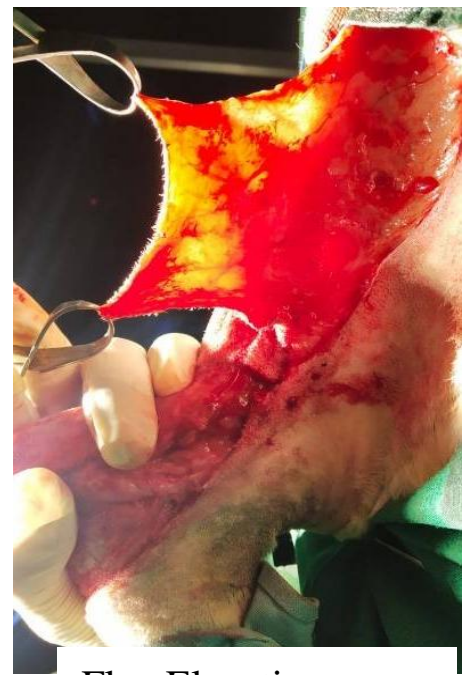

Flap Elevation

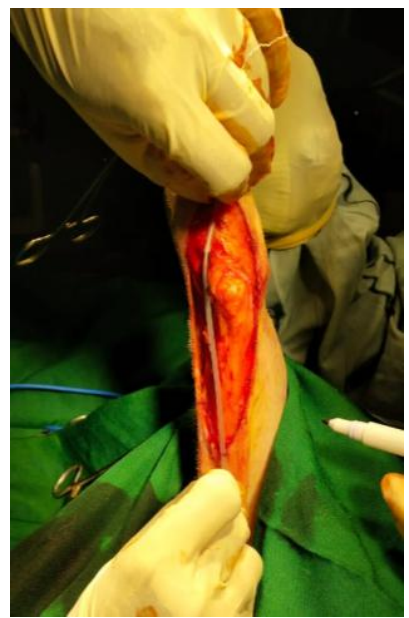

FlapMeasurements

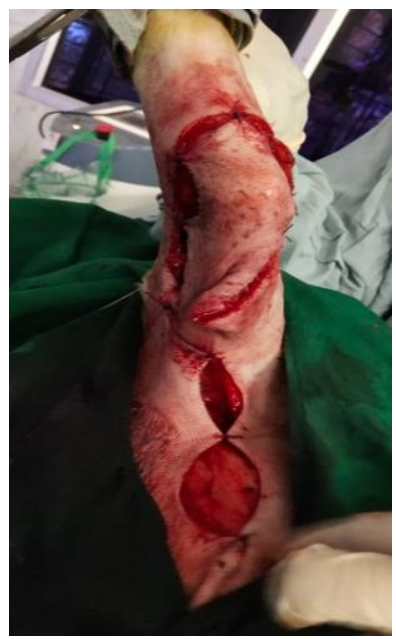

Flap Orientation

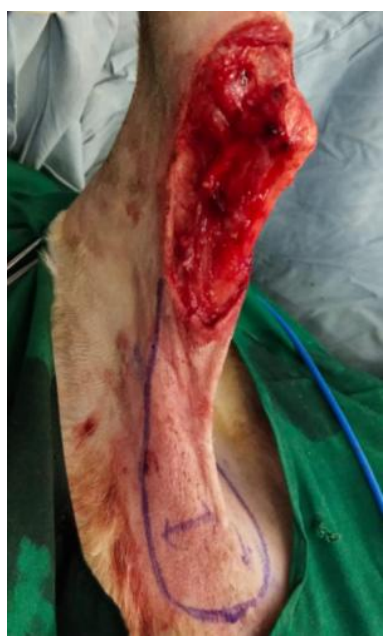

Flap Margination - Elbow fold flap

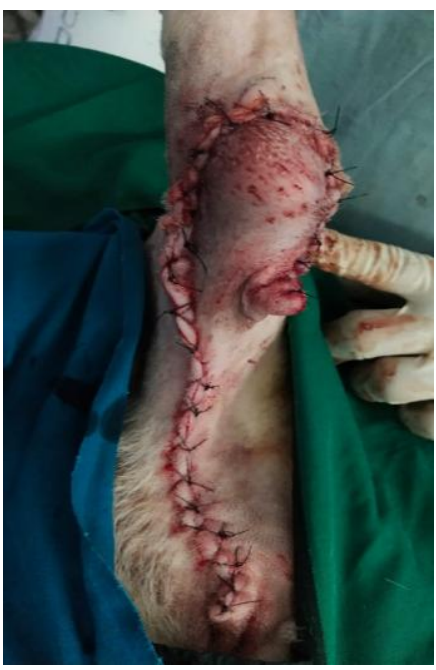

Flap Final outlook
The attachments of the laterally facing (outer) and medially facing (inner) layers of the skin fold to the adjacent limb are divided to produce a U-shaped pedicle graft attached to the trunk. (Pavletic, 1999). This mobilizes skin that can be advanced over large wounds involving the ventral chest or abdomen, or both. The use of skin fold advancement flaps enables direct closure of large skin defects without undue tension and without 
compromising the mobility of the adjacent limb as performed in the present case. Good postoperative care is critical to the success of these procedures (Beldon, 2010). The skin fold is well vascularized and $100 \%$ survival can be expected in most cases, as long as the subdermal plexus is not damaged (De Vosand Butinar, 2008). Drains should be placed at surgery and the wounds protected with a soft, padded bandage (Baines, 1999). Simple rubber tube drains (penrose drains) may be used, although some surgeons prefer closedsuction drains such as the Jackson-Pratt or others. Pain relief will be required usually use of incremental doses of morphine $(0.1 \mathrm{mg} / \mathrm{kg})$ or buprenorphine $(0.01 \mathrm{mg} / \mathrm{kg})$ in dogs. A fentanyl patch, or non-steroidal drugs such as meloxicam may be required if severe pain continues beyond 24 hours after surgery. In the present case tramadol was recommended to the owner. Assuming that the flaps have been created and employed appropriately, failure of the skin flaps to develop a firm connection with underlying tissues will focus tension on the suture line and is the most common cause of partial wound breakdown after the surgery (Hunt et al., 2001). Two layers of sutures are routinely used; a subcutaneous (polydioxanone or polyglactin, interrupted continuous) and skin sutures (polypropylene, single interrupted or cruciate) as done in the present case. Sutures are left in for at least 2 weeks (Fahieand Smith, 1999) Careful planning and atraumatic surgical technique are essential to prevent excessive tension and vascular compromise of skin flaps, especially those based on the subdermal plexus. During flap development, the skin edges is to be manipulated digitally, with skin hooks, or Brown-Adson forceps, and must be apposed correctly (Davidand Runge, 2011). Excessive tension on the suture line or in the middle of the flap can interfere with circulation resulting in ischemic necrosis of either part of, or the entire flap. Necrosis of the distal portion of the flap is more common than complete flap loss. Skin flap tension, to allow revascularization and healing.

\section{References}

Ashraf M. Abu- Seida and Mohamed M. Saleh, 2016. A Gigantic Cutaneous Fibroadenoma in a Dog. Asian Journal of Animal Sciences, 10: 113-119.

Anderson, D.M., Charlesworth, T.C. and White, R.A.S. 2004. A novel axial pattern skin fap based on the lateral thoracic artery in the dog. Vet Comp Orthop Traumatolol. 17: 73 - 77.

Aper, R. and Smeak, D. 2003. Complications and outcome after thoracodorsal axial pattern flap reconstruction of forelimb skin defects in 10 dogs, $1989-2001$. Vet. Surg.32: $378-384$.

Baines, S.J. 1999. Surgical drains. in: D. Fowler, J.M. Williams (Eds.) Manual of Canine and Feline Wound Management and Reconstruction. British Small Animal Veterinary Association, Cheltenham (UK). pp 47-55.

Beldon, P. 2010. Basic Science of wound healing. Surgery. 28 (9):409-412.

Bohling, M.W., Henderson, R.A., Swaim, S.F., Kincaid, S.A. and Wright, J.C. 2004. Cutaneous Wound Healing in the Cat: A macroscopic description and comparison with cutaneous wound healing in the dog. Vet. Surg. 33: 579587.

Bowler, P.G., Duerden, B.I. and Armstrong, D.G. 2001. Wound microbiology and associated approaches to wound management. Clin Microbiol Rev. 14 (2): 244-69.

David, E.H. and Runge, J. 2011. Use of Skin Stretchers to Elongate a Peninsular Thoracodorsal Axial Pattern Flap for Antebrachial Wound Closure in a Dog Vet. Surg. 40:352-356.

De Vos, J. P. and Butinar, J. 2008. A transposition flap for reconstructing a 
large skin defect over the stifle and proximal tibia in a dog after removal of a hemangiopericytoma. Vlaams Diergeneeskundig Tijdschrift. 78.242253.

Fahie, M.A. and Smith, M.M. 1999. Axial pattern flap based on the cutaneous branch of the superficial temporal artery in dogs: an experimental study and case report. Vet. Surg.28: 141 - 147.

Hunt, G.,Geraldine, B., Penelope, L.C., Julius, M., Liptak. and Richard, M. 2001. Skin Fold Advancement Flaps for Closing Large Proximal Limb and trunk defects in dogs and cats. Veterinary surgery. 30:440-448.

Pavletic, M.M. 1999. Local Flaps. In: Michael M., Pavletic M. (editors). Atlas of Small Animal Reconstructive Surgery, 2nd ed. W.B. Saunders Co, Philadelphia pp $108-113$.

Reetz, J.A., Seiler, G., Mayhew, P.D. and Holt, D.E. 2006. Ultrasonographic and color - flow Doppler ultrasonographic assessment of direct cutaneous arteries used for axial pattern skin flaps in dogs. J Am Vet Med Assoc228: 1361 - 1366.

\section{How to cite this article:}

Gokulakrishnan, M., L. Nagarajan, Denise A. Almeida and Gowsalya, S. 2020. Surgical Excision of Fibroma Followed by Elbow Fold Flap in a Non-descriptive Dog. Int.J.Curr.Microbiol.App.Sci. 9(03): 1845-1849. doi: https://doi.org/10.20546/ijcmas.2020.903.213 